\title{
Radio-opaque pellets as faecal markers for faecal fat estimation in malabsorption
}

\author{
F. G. SIMPSON, G. P. HALL, J. KELLEHER, AND M. S. LOSOWSKY \\ From the Department of Medicine, University of Leeds, St James's Hospital, Leeds
}

SUMMARY Thirty-seven patients undergoing routine investigation for malabsorption were given radio-opaque pellets (ROP) which were compared with polyethylene glycol and chromic oxide as continuous faecal markers. Percentage recovery of all markers showed a wide range. The recovery of all markers was very similar, and radio-opaque pellet-corrected daily faecal fat correlated very closely with PEG- and chromic oxide-corrected fat results. Estimation of ROP is precise, simple, and minimisesfaecal handling. ROP are suitable for routine use in faecal fat studies and have advantages over markers used at present.

The estimation of faecal fat output has long been one of the mainstays in diagnosis and management of malabsorption. It has been recognised for many years that because of variability of bowel habit accurate measurement of faecal fat output requires either prolonged periods of stool collection or the use of some form of faecal marker (Walker et al., 1971). Intermittent markers such as carmine red have never become popular and their usefulness has been questioned (Rose, 1964). Continuous markers are more widely used, though an equilibration period is necessary. The ideal marker should be inert, nontoxic, non-absorbed, non-metabolised, have negligible bulk and mix thoroughly with the intestinal contents, it should be closely associated with the substance to be measured and easy to estimate (Whitby and Lang, 1960; Fordtran, 1966). A wide variety of substances has been used as faecal markers in man, including iron oxide (Bergeim, 1926), chromic oxide (Kreula, 1947), titanium oxide (Fournier, 1950), phenol red (Reynell and Spray, 1956), polyethylene glycol (Borgström et al., 1957), succinylsulphathiazole (Pearson, 1958), lanthanum-140 (Hayes et al., 1964), barium sulphate (Dick, 1967), cerium 144 (Knapka et al., 1967), cuprous thiocyanate (Dick, 1969), inulin (Miller and Schedl, 1970), mannitol (Miller and Schedl, 1970), and glycerol triether (Gerskowitch and Russell, 1974). Recently Branch and Cummings (1978) reported the use of radioopaque pellets in faecal calcium balance studies in five normal subjects. They found a very close correlation of results using ROP and chromic oxide $\left(\mathrm{Cr}_{2} \mathrm{O}_{3}\right)$ and suggested that ROP are suitable for

Received for publication 1 February 1979 routine use in calcium balance studies. However, ROP have not been validated for use in estimation of faecal fat and no studies have been performed in patients with malabsorption. We report a study comparing ROP and two established and widely used markers $\left(\mathrm{Cr}_{2} \mathrm{O}_{3}\right.$ and polyethylene glycol 4000 (PEG)) in 37 patients suspected of malabsorption, who were undergoing routine faecal fat measurements on a general medical ward.

\section{Methods}

\section{PATIENTS}

Thirty-seven patients with suspected malabsorption were studied (13 liver disease, 10 small bowel disease, five alcoholics, three post-gastric surgery diarrhoea, two pancreatic insufficiency, two non-specific diarrhoea, one ankylosing spondylitis, and one hypobetalipoproteinaemia).

\section{PROCEDURE}

Each patient received a constant fat intake throughout the study, the intakes ranging from 65 to $130 \mathrm{~g} /$ day (mean $86.5 \mathrm{~g} /$ day). All 37 patients received eight radio-opaque pellets three times a day with each main meal. The ROP were prepared from $3 \mathrm{~mm}$ external diameter Portex radio-opaque tubing cut into $5 \mathrm{~mm}$ lengths. (ROP can now be purchased ready-made.) Twenty-three of these patients were also given chromic oxide capsules (Sandoz Products Ltd, London) $500 \mathrm{mg}$ tds, and 34 were given polyethylene glycol 4000 (Sandoz Products Ltd, London) $500 \mathrm{mg}$ tds. Twenty patients had all three markers. After an equilibration period of five days, stools were collected for two-day periods into strong polythene bags which fitted directly onto a 
commode. A total of 87 two-day collections was made.

The pooled two-day stools were homogenised with water while in the polythene bags using a Colworth Stomacher 3500. Aliquots were removed for $\mathrm{Cr}_{2} \mathrm{O}_{3}$ and PEG assay and stored at $-20^{\circ} \mathrm{C}$. The collection bag was radiographed and the ROP counted. Analysis of the aliquots for $\mathrm{Cr}_{2} \mathrm{O}_{3}$ was performed by the method of Bolin et al. (1952) and for PEG by the method of Wilkinson (1971). All assays were performed in duplicate. Faecal fat was determined by the method of van de Kamer et al. (1949).

\section{Results}

All markers were well tolerated and no side-effects were observed.

\section{RECOVERY OF MARKERS}

Figure 1 shows the distribution of recovery of each marker in individual two-day collections expressed as a percentage of the oral dose of marker administered in two days. Mean recovery of ROP was $98.09 \%$ (SD $38.05 \%$ ), of $\mathrm{Cr}_{2} \mathrm{O}_{3} \quad 100 \cdot 24 \%$ (SD $43.18 \%$ ), and of PEG $93.81 \%$ (SD $41.97 \%$ ). The range of recovery was wide but was similar for each marker: $\mathrm{ROP} 33.3$ to $241.7 \%, \mathrm{Cr}_{2} \mathrm{O}_{3} 31.0$ to $250.0 \%$, PEG 28.0 to $282.3 \%$.

The distribution of recoveries was very similar for

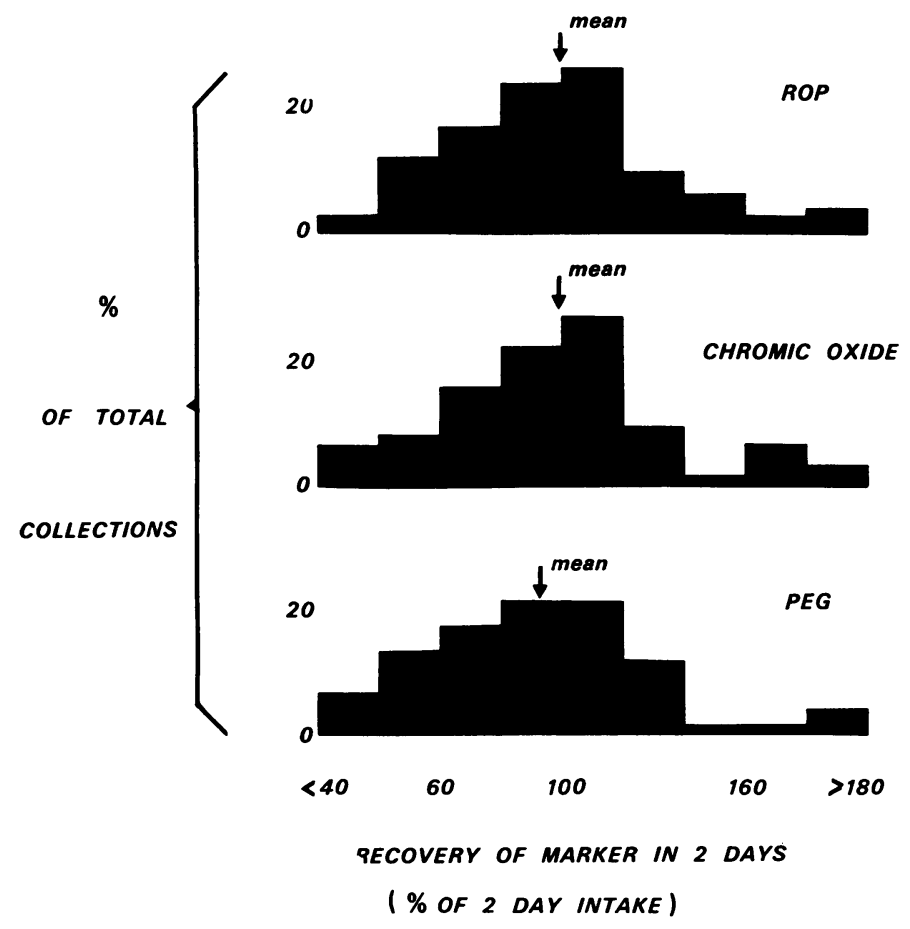

all three markers and for each case the distribution was not significantly different from a normal curve.

Recovery of ROP in individual collections correlated very closely with recovery of $\mathrm{Cr}_{2} \mathrm{O}_{3}(r=0.948)$ (Fig. 2) and also with recovery of PEG $(r=0.922)$.

\section{CORRECTED FAECAL FAT EXCRETION}

Figures 3 and 4 show the correlation of ROPcorrected faecal fat excretion (expressed as percentage of dietary intake) with $\mathrm{Cr}_{2} \mathrm{O}_{3}$-corrected faecal fat and with PEG-corrected faecal fat for each two-day collection. ROP-corrected faecal fat correlated extremely closely with both $\mathrm{Cr}_{2} \mathrm{O}_{3}$ - and PEGcorrected values, and, assuming the results using the established markers to be correct, there are very few falsely normal or abnormal results when using ROP. A similarly close correlation was also seen when $\mathrm{Cr}_{2} \mathrm{O}_{3}$ corrected faecal fat was compared with PEGcorrected faecal fat.

\section{Discussion}

ROP are inert, non-toxic, not absorbed or metabolised, their bulk is negligible, and they seem to equilibrate well with the intestinal contents, as compared with the established markers $\mathrm{Cr}_{2} \mathrm{O}_{3}$ and PEG.

There was no significant difference in the performance of any of the three markers used in this study. 


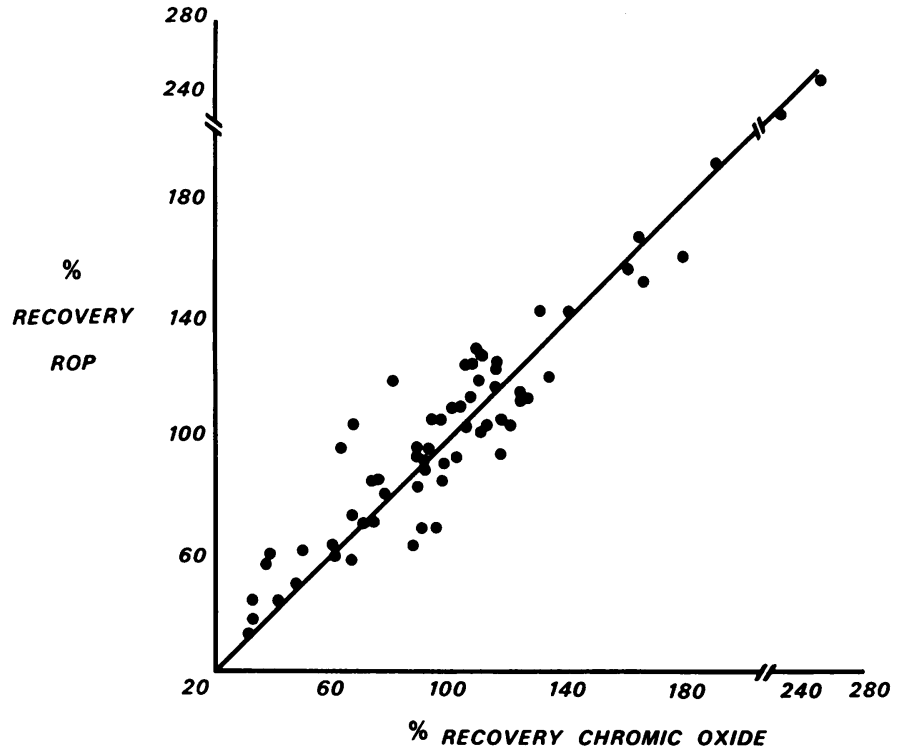

DAILY FAECAL FAT (\% DIETARY INTAKE)

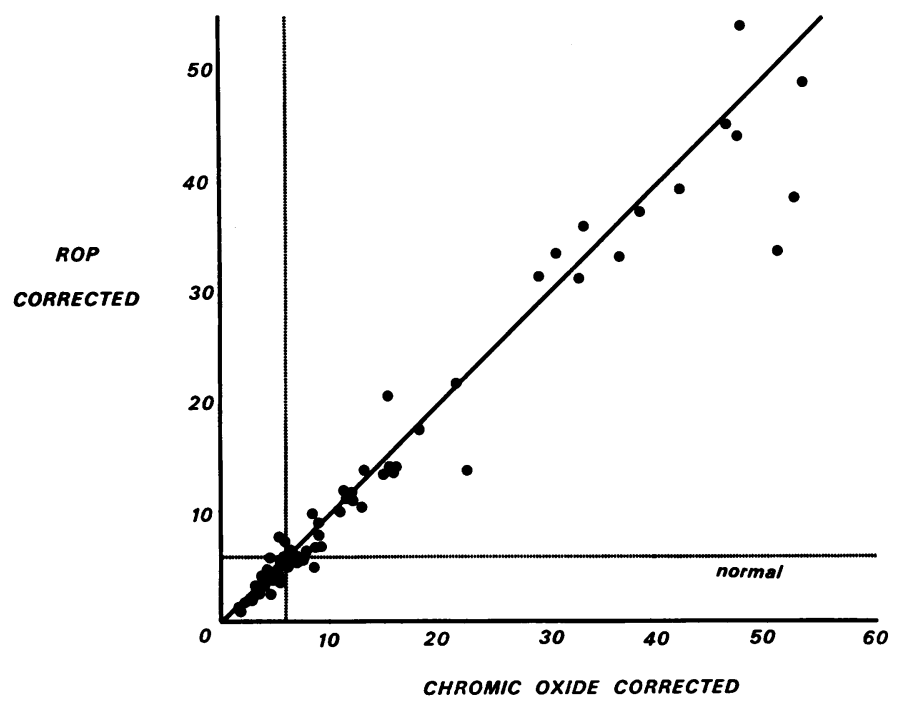

Fig. 2 Comparison of faecal recovery of $\mathrm{ROP}$ and $\mathrm{Cr}_{2} \mathrm{O}_{3}$ in two-day collections expressed as percentage of dose of each administered in two days.

Fig. 3 Comparison of ROP-corrected and $\mathrm{Cr}_{2} \mathrm{O}_{3}$-corrected faecal fat (expressed as percentage of dietary intake) for individual two-day collections.
All were well tolerated and recovery of all three in the faeces was very similar both in range and distribution. Recovery of all markers in individual two-day collections also correlated closely with each other, as did the results of corrected faecal fat outputs with each marker. Although theoretically ROP might not travel closely with the fat in the bowel lumen, for practical purposes ROP perform as well as PEG or $\mathrm{Cr}_{2} \mathrm{O}_{3}$ for faecal fat studies in patients with gastrointestinal disease. This extends the find- ings of Branch and Cummings (1978) for calcium balances in normal subjects.

The advantages of ROP over established markers are simplicity and safety of estimation, and minimising of faecal handling and use of laboratory time and facilities. Faecal fat determinations have been further simplified in the present study by using the Colworth Stomacher for specimen homogenisation. Combining this technique with ROP the sample can be collected, homogenised, and the marker estimated 


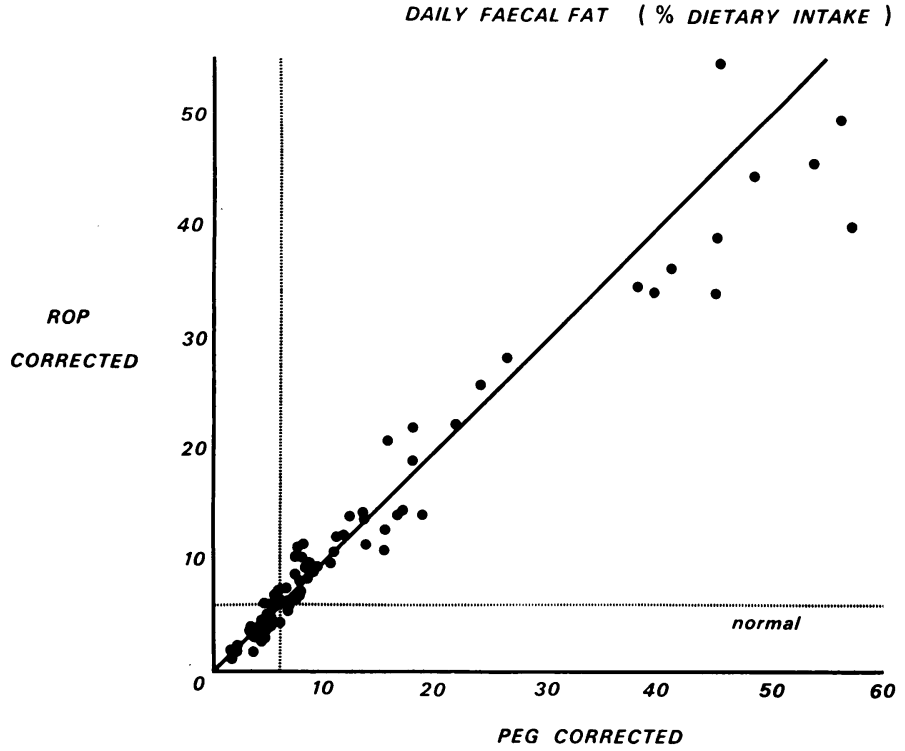

Fig. 4 Comparison of ROP-corrected and PEG-corrected faecal fat (expressed as percentage of dietary intake) for individual two-day collections.

in the same polythene bag without any transfer of sample. After removal of an aliquot for faecal fat determination the bag can then be sealed and discarded. This further reduces the handling of faecal samples.

We conclude that ROP are suitable as nonabsorbable markers for faecal fat studies, and offer several distinct advantages over other markers presently in use.

\section{References}

Bergeim, O. (1926). Intestinal chemistry. IV. A method for the study of food utilization or digestibility. Journal of Biological Chemistry, 70, 29-33.

Bolin, D. W., King, R. P., and Klosterman, E. W. (1952). A simplified method for the determination of chromic oxide $\left(\mathrm{Cr}_{2} \mathrm{O}_{3}\right)$ when used as an index substance. Science, 116, 634-635.

Borgström, B., Dahlqvist, A., Lundh, G., and Sjövall, J. (1957). Studies of intestinal digestion and absorption in the human. Journal of Clinical Investigation, 36, 1521-1536.

Branch, W. J., and Cummings, J. H. (1978). Comparison of radio-opaque pellets and chromium sesquioxide as inert markers in studies requiring accurate faecal collections. Gut, 19, 371-376

Dick, M. (1967). Use of barium sulphate as a continuous marker for faeces. Journal of Clinical Pathology, 20, 216218.

Dick, M. (1969). Use of cuprous thiocyanate as a short-term continuous marker for faeces. Gut, 10, 408-412.

Fordtran, J. S. (1966). Marker perfusion techniques for measuring intestinal absorption in man. Gastroenterology, 51, 1089-1093.

Fournier, P. (1950). De l'emploi de l'oxyde de titane pour l'étude quantitative de l'absorption intestinale. Comptes Rendus Hebdomadaires des Séances de l'Académie des Sciences, 231, 1343-1345.

Gerskowitch, V. P., and Russell, R. I. (1974). Tritiated glycerol triether as an oil phase marker in man. Journal of Lipid Research. 15, 432-435.

Hayes, R. L., Carlton, J. E., and Nelson, B. (1964). Lanthanum-140 as a measure of the completeness of stool collections. Demonstration of delayed excretion of iron-59. Journal of Nuclear Medicine, 5, 200-208.

Kamer, J. H. van de, Huinink, H. ten Bokkel, and Weyers, W. A. (1949). Rapid method for the determination of fat in feces. Journal of Biological Chemistry, 177, 347-355.

Knapka, J. J., Barth, K. M., Brown, D. G., and Cragle, R. G. (1967). Evaluation of polyethylene, chromic oxide, and cerium-144 as digestibility indicators in Burros. Journal of Nutrition, 92, 79-85.

Kreula, M. S. (1947). Absorption of carotene from carrots in man and the use of the quantitative chromic oxide indicator method in the absorption experiments. Biochemical Journal, 41, 269-273.

Miller, D. L., and Schedl, H. P. (1970). Total recovery studies of nonabsorbable indicators in the rat small intestine. Gastroenterology, 58, 40-46.

Pearson, J. W. (1958). Continuous perfusion and absorption in the jejunum of the dog. Journal of Applied Physiology, 13, 313-316.

Reynell, P. C., and Spray, G. H. (1956). The simultaneous measurement of absorption and transit in the gastrointestinal tract of the rat. Journal of Physiology, 131, 452462.

Rose, G. A. (1964). Experiences with the use of interrupted carmine red and continuous chromium sesquioxide marking of human faeces with reference to calcium, phosphorus and magneisum. Gut, 5, 274-279.

Walker, B. E., Kelleher, J., Davies, T., and Losowsky, M. S. (1971). Chemical faecal fat using single stools. Scandinavian Journal of Gastroenterology, 6, 277-280.

Whitby, L. G., and Lang, D. (1960). Experience with the chromic oxide method of fecal marking in metabolic balance investigations on humans. Journal of Clinical Investigation, 39, 854-863.

Wilkinson, R. (1971). Polyethylene glycol 4000 as a continuously administered non-absorbable faecal marker for metabolic balance studies in human subjects. Gut, 12, 654660. 